\title{
Embryonic Neurons Adapt to the Inhibitory Proteoglycan Aggrecan by Increasing Integrin Expression
}

\author{
Maureen L. Condic, ${ }^{1}$ Diane M. Snow, ${ }^{2}$ and Paul C. Letourneau ${ }^{3}$ \\ ${ }^{1}$ Department of Neurobiology and Anatomy, University of Utah, School of Medicine, Salt Lake City, Utah 84132-0002, \\ 2Department of Anatomy and Neurobiology, The University of Kentucky, Lexington, Kentucky 40536-0298, and \\ ${ }^{3}$ Department of Neuroscience, University of Minnesota, Minneapolis, Minnesota 55455
}

The primary mediators of cell migration during development, wound healing and metastasis, are receptors of the integrin family. In the developing and regenerating nervous system, chondroitin sulfate proteoglycans (CSPGs) inhibit the integrindependent migration of neuronal growth cones. Here we report that embryonic sensory neurons cultured on the growthpromoting molecule laminin in combination with the inhibitory CSPG aggrecan rapidly adapt to inhibition. Adaptation is associated with a two- to threefold increase in the levels of RNA and surface protein for two laminin receptors, integrin $\alpha 6 \beta 1$ and $\alpha 3 \beta 1$, indicating that integrin expression is regulated by aggre- can. Increased integrin expression is associated both with increases in neuronal cell adhesion/outgrowth and with decreases in the ability of aggrecan to inhibit cell adhesion. Directly increasing integrin expression by adenoviral infection is sufficient to eliminate the inhibitory effects of aggrecan, indicating that upregulation of integrin receptors may promote neuronal regeneration in the presence of inhibitory matrix components.

Key words: integrin; CSPG; aggrecan; adaptation to inhibition; proteoglycan; regeneration; adenovirus-mediated gene transfer
Many matrix components are considered either growth promoting or inhibiting based on the ability of purified protein to support or block neurite outgrowth in culture. It is becoming increasingly evident, however, that the precise nature of a neuron's response to individual matrix proteins depends on both the context in which they are encountered and the past history of the individual neuron (Snow and Letourneau, 1992; Condic and Letourneau, 1997). Recent work has shown that a number of molecules can have either an attractive or a repulsive effect on neuronal outgrowth, depending on the levels of cyclic nucleotides present in the growth cone (Song et al., 1998). These results suggest that the history of a growth cone or the precise balance of molecules that it encounters can greatly influence the growth response.

Luo and Raper (1994) distinguish between two types of inhibitory elements for growth cones: molecules that directly impair intrinsic motility and molecules that interfere with substratum adhesion. Chondroitin sulfate proteoglycans (CSPGs) are a major class of inhibitory matrix proteins that have been proposed to act either as adhesion-inhibiting molecules or through receptors to directly affect cell motility (Luo and Raper, 1994; Faissner and Steindler, 1995; Hoke and Silver, 1996). In the adult CNS, the upregulation of CSPGs after injury is correlated with the failure of axons to extend despite the continued presence of growth-

\footnotetext{
Received July 8, 1999; revised Aug. 31, 1999; accepted Sept. 3, 1999.

This work was supported by a grant from the Spinal Cord Research Foundation and National Institutes of Health (NIH) Grant NS38138-01 to M.L.C., NIH Grant EY10545 and a grant from the American Paralysis Association to D.M.S., and NIH Grant HD19950 and a grant from the Minnesota Medical Foundation to P.C.L. We thank Drs. H. J. Yost, S. B. Kater, T. Diffenbach, and G. Gallo for critical reading of this manuscript; A. Cooke, P. Atkinson, K. Roche, and Dr. J. Gurwell for assistance with experiments; Dr. L. F. Reichardt for integrin antibodies; and Dr. C. Buck for adenoviral constructs.

Correspondence should be addressed to Dr. M. L. Condic, Department of Neurobiology and Anatomy, University of Utah, School of Medicine, 50 N. Medical Drive, Salt Lake City, UT 84132-0002. E-mail: mcondic@alta.med.utah.edu. Copyright (C) 1999 Society for Neuroscience 0270-6474/99/1910036-08\$05.00/0
}

promoting molecules such as laminin (for review, see Hoke and Silver, 1996), suggesting that elevated expression of CSPGs contributes to the inability of neurons to regenerate after injury.

Aggrecan is one of the major CSPGs expressed in the CNS and PNS of embryos and adults (Caterson et al., 1983; Oakley and Tosney, 1991; Schwartz et al., 1996). Aggrecan is inhibitory to the extension of retinal and sensory neurons in culture (Snow and Letourneau, 1992; Challacombe et al., 1997). Embryonic neurons can adapt to the inhibitory effects of aggrecan over time when aggrecan is presented with growth-promoting molecules such as laminin (Snow et al., 1990a; Snow and Letourneau, 1992). Adaptation could be accomplished either through the upregulation of receptors for growth-promoting ligands such as laminin or through the downregulation of neuronal receptors for aggrecan. Although the effects of aggrecan are likely to be mediated in part through a receptor-based mechanism (Snow et al., 1994; Balsamo et al., 1995; Ernst et al., 1995), aggrecan receptors have not yet been identified. Neuronal outgrowth is mediated predominantly by receptors of the integrin family (Letourneau et al., 1994), which bind to a wide range of ECM and cell-surface ligands. In sensory neurons, neurite outgrowth on ECM proteins such as laminin is entirely dependent on integrin function (Tomaselli et al., 1993), suggesting that increased integrin expression in response to a combination of aggrecan and laminin may allow neurons to adapt to inhibition and extend on laminin. In this work, we have examined the expression of integrins in response to aggrecan to determine the role of integrin regulation in neuronal adaptation to inhibitory proteoglycans.

\section{MATERIALS AND METHODS}

Cell culture and substratum preparation. dorsal root ganglia were dissected from embryonic day 12 chicks and dissociated with brief trypsin treatment (Gomez and Letourneau, 1994). Dissociated cells were preplated on tissue culture plastic in Ham's F12 media containing $10 \%$ calf serum for $3 \mathrm{hr}$ at $37^{\circ} \mathrm{C}$ to remove more adherent non-neuronal cells (Barres et 
al., 1988). After $3 \mathrm{hr},>95 \%$ of cells remaining in suspension are neuronal. Neurons in suspension were harvested, rinsed in PBS, and cultured overnight on glass coverslips in serum-free media as described (Gomez and Letourneau, 1994). NGF was present in all cultures at $10 \mathrm{ng} / \mathrm{ml}$, concentrations that are saturating for the TrkA receptor. For overnight cultures, glass coverslips were coated for $1 \mathrm{hr}$ at room temperature with Engelbreth-Holm-Swarm tumor laminin (gift of Dr. S. Palm, University of Minnesota) at $20 \mu \mathrm{g} / \mathrm{ml}(\mathrm{LM})$ or $1 \mu \mathrm{g} / \mathrm{ml}$ (low LM), or Fibronectin (Life Technologies, Gaithersburg, MD) at $20 \mu \mathrm{g} / \mathrm{ml}$ in PBS. Aggrecancontaining substrata for culture were prepared by coating coverslips with chick embryonic limb-bud aggrecan (gift of Dr. David Corrino, Case Western Reserve University) at $50 \mu \mathrm{g} / \mathrm{ml}$ in PBS for $1 \mathrm{hr}$, followed by laminin at $20 \mu \mathrm{g} / \mathrm{ml}$ for $1 \mathrm{hr}(\mathrm{PG} / \mathrm{LM})$. These treatments resulted in the following bound concentrations of protein: (LM) $300 \mathrm{ng} / \mathrm{cm}^{2}$ laminin; (low LM) $30 \mathrm{ng} / \mathrm{cm}^{2}$ laminin; (PG/LM) $300 \mathrm{ng} / \mathrm{cm}^{2}$ laminin, $180 \mathrm{ng} / \mathrm{cm}^{2}$ aggrecan. These concentrations are likely to be above those predicted to form a molecular monolayer. Binding of laminin and aggrecan to coverslips and 96-well plates (below) was determined by inclusion of ${ }^{3} \mathrm{H}$ labeled laminin and ${ }^{35} \mathrm{~S}$-labeled aggrecan at known specific activities in the coating medium, followed by extraction of the bound protein with $10 \%$ SDS and scintillation counting. Metabolically labeled chick embryonic aggrecan was obtained from Dr. David Corrino. Laminin was labeled with ${ }^{3} \mathrm{H}$ as previously described (Snow and Letourneau, 1992).

$R N A$ and protein analysis. RNA was isolated from $\sim 10^{7}$ neurons by lysing the cells in situ in a phenol/SDS buffer (TriReagent, Molecular Research Center). RNA concentration was determined by UV absorption at $260 \mathrm{~nm} ; 10 \mu \mathrm{g}$ samples were analyzed on agarose gels and transferred to nylon membrane by pressure blot (Stratagene, La Jolla, CA) using standard procedures. Integrin $\alpha 6, \alpha 3$, and GAPDH transcripts were detected with ${ }^{32} \mathrm{P}$-labeled oligonucleotide probes. Films and blots were quantitated using a Bio-Rad GS-700 imaging densitometer, a GS363 phosphoimager, and NIH image 1.55 analysis software.

Cell surface receptor was labeled with biotin and immunoprecipitated using published methods and antibodies specific for $\alpha 6-$ and $\alpha 3$-integrin (de Curtis et al., 1991). Immunoprecipitated proteins were sizefractionated under reducing conditions on acrylamide gels and electrophoretically transferred to nitrocellulose membrane using standard protocols. Biotin-labeled proteins were detected using streptavidin conjugated to HRP and a chemiluminescent reagent (Pierce, Rockford, IL) followed by exposure to film. Ratios of protein determined from quantitation of film were comparable to those obtained by direct phosphoimaging of chemiluminescently detected proteins (data not shown).

Cell adhesion assays. Cells were cultured overnight on either laminin, low laminin, or laminin in combination with low levels of aggrecan (see Cell culture and substratum preparation). Culture on both PG/LM (see Fig. 3) and low LM (Condic and Letourneau, 1997) increase integrin expression, apparently by different molecular mechanisms. After culture, neurons were removed from the substratum by a brief treatment with calcium-free media and gentle scraping in media containing $10 \%$ serum at $4^{\circ} \mathrm{C}$ to prevent the internalization of cell-surface integrins. Cells were spun down at $4^{\circ} \mathrm{C}$, resuspended, and maintained at $4^{\circ} \mathrm{C}$ until plating. To measure cell adhesion, 96-well plastic plates (Dynatech Immunolon) were coated with laminin (40 $\mu \mathrm{g} / \mathrm{ml}$ in PBS for $1 \mathrm{hr})$, low laminin (2 $\mu \mathrm{g} / \mathrm{ml}$ laminin in PBS for $1 \mathrm{hr}$ ), or aggrecan and laminin (aggrecan at 50 $\mu \mathrm{g} / \mathrm{ml}$ in PBS for $1 \mathrm{hr}$, followed by laminin at $40 \mu \mathrm{g} / \mathrm{ml}$ in PBS for $1 \mathrm{hr}$ ). On the basis of binding of isotopically labeled proteins, these concentrations of applied protein resulted in surface densities of bound protein similar to those used for culturing (data not shown). The plates were rinsed, blocked with PBS containing $5 \mathrm{mg} / \mathrm{ml} \mathrm{BSA}$ and $0.2 \%$ sodium azide for $1 \mathrm{hr}$, and rinsed extensively. Cells were applied at 10,000 cells per well and allowed to adhere for $3 \mathrm{hr}$ at $37^{\circ} \mathrm{C}$. Wells were rinsed once with $100 \mu \mathrm{l}$ PBS and then incubated for $10 \mathrm{~min}$ in PBS containing 2 $\mu \mathrm{g} / \mathrm{ml} \quad 2^{\prime}, 7^{\prime}$-bis-(2-carboxyethyl)-5-(and-6)-carboxyfluorescein, acetoxymethyl ester (Molecular Probes, Eugene, OR) followed by detection of fluorescein emission using a microplate fluorescence reader (Cytofluor II; Biosearch/Millipore).

To determine the effect on neuronal adhesion of applying proteins to the substrata in different order (see Fig. 2), aggrecan was bound to 96-well plates before, after, or in combination with laminin. Aggrecan and laminin binding to the substrata were determined for all applied concentrations by inclusion of isotopically labeled protein (see Cell culture and substratum preparation). All three treatments resulted in identical concentrations of bound laminin $\left(300 \mathrm{ng} / \mathrm{cm}^{2}\right)$ for all concentrations of bound aggrecan. Plates were prepared as follows. BEFORE: aggrecan was applied first at concentrations of $1,2.5,5$, and $50 \mu \mathrm{g} / \mathrm{ml}$, resulting in bound concentrations of aggrecan equal to $20,60,100$, and $180 \mathrm{ng} / \mathrm{cm}^{2}$ followed by rinsing and application of laminin at $40 \mu \mathrm{g} / \mathrm{ml}$. AFTER: laminin was applied first at a concentration of $40 \mu \mathrm{g} / \mathrm{ml}$, followed by rinsing and application of aggrecan at a concentration of 10 , 25,100 , and $500 \mu \mathrm{g} / \mathrm{ml}$, resulting in bound concentrations of aggrecan equal to those achieved by application of aggrecan before laminin (i.e., $20,60,100$, and $180 \mathrm{ng} / \mathrm{cm}^{2}$ ). MIXED: laminin at $40 \mu \mathrm{g} / \mathrm{ml}$ was mixed with aggrecan at 5,15 , and $25 \mu \mathrm{g} / \mathrm{ml}$ for $30 \mathrm{~min}$ before application to the plates, resulting in bound concentrations of aggrecan equal to 20,60, and $100 \mathrm{ng} / \mathrm{cm}^{2}$. Note that only three concentrations were tested because aggrecan concentrations higher than $25 \mu \mathrm{g} / \mathrm{ml}$ inhibited binding of laminin (data not shown).

Cell outgrowth assays. To determine neurite initiation (see Fig. 1), cells were cultured on either LM or PG/LM substrata (see Cell culture and substratum preparation) for 3 or $20 \mathrm{hr}$, and 10 random fields were recorded as video images. The total number of cell bodies and neurites greater than one cell diameter in length were counted for each field and expressed as the average number of neurites per cell. To determine the rate of neurite extension, cells were cultured as above on either LM or PG/LM substrata for 3 or $20 \mathrm{hr}$ and moved to a heated microscope stage. Dishes were allowed to equilibrate for $30 \mathrm{~min}$, then images were captured for $1 \mathrm{hr}$, one image every $5 \mathrm{~min}$. Images were captured every $5 \mathrm{~min}$ to confirm that the path of the neuron was linear over the culture period, so the average rate of growth cone advance could be determined from the linear distance traversed. The rate of axon extension was determined from the distance traversed by the growth cone in $1 \mathrm{hr}$ as measured between the positions of the leading edge of the growth cone at the beginning and end of the period of image acquisition using Image- 1 software. To measure outgrowth of neurons with different levels of integrin expression (see Fig. 4), neurons were cultured on LM, PG/LM, or low LM substrata overnight, as described above (Cell adhesion assays), and were subsequently replated on laminin, low laminin, or $\mathrm{PG} / \mathrm{LM}$ containing substrata and allowed to extend axons for $3 \mathrm{hr}$. Cultures were fixed with $4 \%$ paraformaldehyde, and the percentage of cells with neurites one cell diameter or greater in length was determined.

Adenoviral infection. Replication-deficient adenoviral constructs were obtained from the laboratory of Dr. Clayton Buck (Wistar Institute). The integrin-expressing adenoviral constructs were prepared using standard methods (Graham and Prevec, 1995). Briefly, full-length mouse $\alpha 1$ integrin or $\beta$-galactosidase (as a control) cDNA were cloned into the pAd.CMV-link plasmid under the control of the cytomegalovirus immediate early enhancer/promoter element. This promoter has been shown to yield efficient expression of transgenes in chick embryonic neurons (Yamagata et al., 1994) and in the nervous systems of other species. NIH 293 cells were cotransfected with linearized pAd.CMV-link plasmid (with insert) and the replication-deficient sub 360 or dl70001 adenoviral backbone. Recombinant virus was collected from plaques, and the inserts were confirmed by PCR. The virus was subjected to three rounds of plaque purification to ensure that a single recombinant was selected and further purified by centrifugation on a cesium gradient. The titer of the purified recombinant virus was determined with plaque assay.

Embryonic chick neurons were cultured on laminin $\left(300 \mathrm{ng} / \mathrm{cm}^{2}\right)$ substrata and infected overnight at a viral concentration of $8 \times 108$ $\mathrm{pfu} / \mathrm{ml}$. After $16 \mathrm{hr}$, the virus was removed, and neurons were cultured for an additional $48 \mathrm{hr}$ to insure strong expression of the transgene. Cell surface expression of the integrin transgene was confirmed by staining cells live with antibodies that specifically recognize mouse $\alpha 1$-integrin (Ha31/8; PharMingen, San Diego, CA). All cells in the mouse $\alpha 1$ integrin-infected culture expressed the transgenic protein at the cell surface. Endogenous $\alpha 1$ is expressed at low levels in both control and $\alpha 1$-integrin-infected cultures (see Fig. $5 B$ ). $\beta$-galactosidase expression was confirmed by antibody staining (5 Prime to 3 Prime Biologicals) of fixed and Triton X-100-extracted cells. Infected neurons were removed from the dishes as described above (Cell adhesion assays), replated on substrata containing laminin or PG/LM, and assayed for outgrowth in 3 $\mathrm{hr}$ as above (Cell outgrowth assays). Levels of total $\alpha 1$-integrin expressed at the cell surface were determined by immunoprecipitation of cellsurface biotinylated $\alpha 1$-protein using an antibody that recognizes both the exogenous (mouse) and the endogenous (chick) $\alpha 1$ subunits (Chemicon, Temecula, CA), followed by Western analysis as described (RNA and protein analysis). 


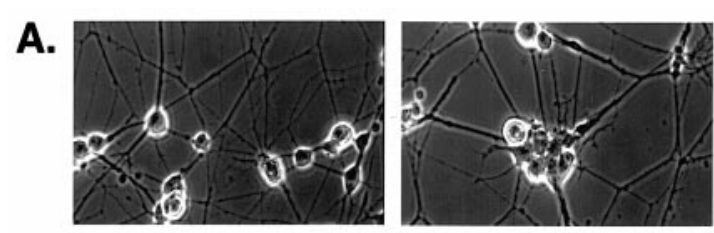

B.
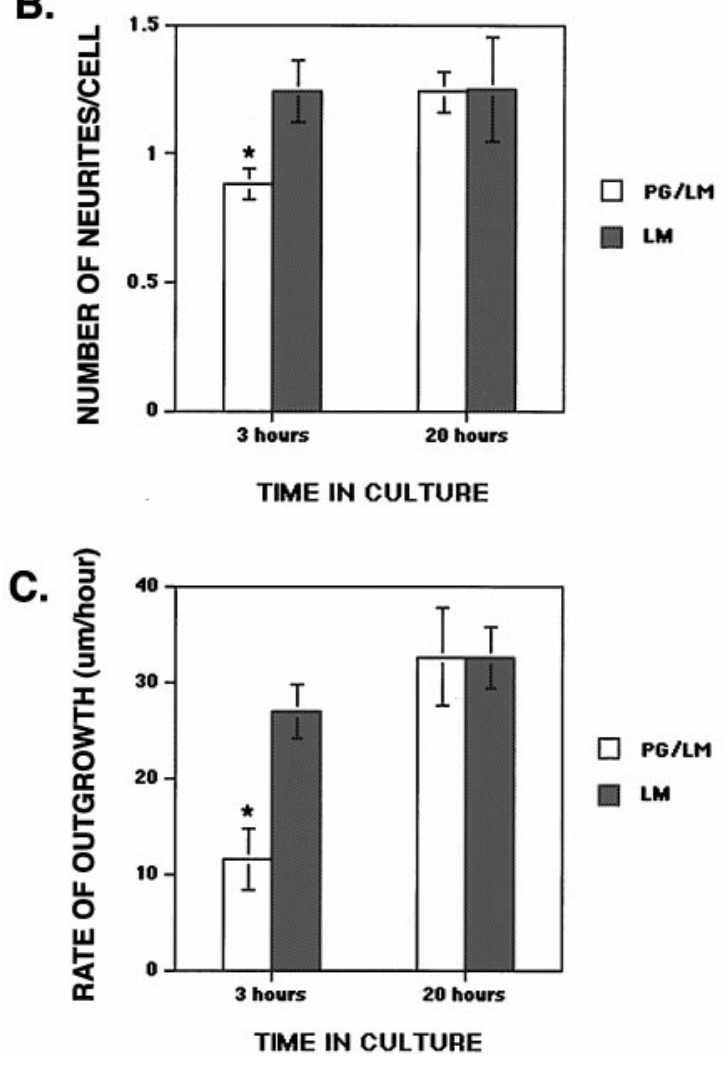

Figure 1. Neurons cultured on substrata containing a low concentration of the inhibitory proteoglycan aggrecan adapt to inhibition and extend neurites. $A$, Neurons were cultured on substrata containing either laminin alone (left) or laminin in combination with aggrecan (right). After 16-20 $\mathrm{hr}$ in culture, neurons have extended axons on both substrata. Outgrowth was less prof use and axons were more fasciculated on substrata containing aggrecan relative to outgrowth on laminin alone. $B$, The initiation of neurites is delayed on substrata containing aggrecan. At $3 \mathrm{hr}$, significantly fewer cells ( $p<0.002, t$ test) have initiated neurites on substrata containing aggrecan relative to cells on laminin alone. By $6 \mathrm{hr}$ in culture, the number of neurites initiated on aggrecan-containing substrata has greatly increased, suggesting that the neurons have adapted to inhibition. Means + SEMs of three experiments, each measuring at least 174 neurons/ condition, are given. $C$, The rate of axon extension on laminin at $3 \mathrm{hr}$ in culture is reduced by the presence of aggrecan $(p<0.001, t$ test $)$, but by $20 \mathrm{hr}$ in culture the rate of outgrowth on the two substrata is identical. Means + SEMs of three experiments, each measuring at least 14 neurons/ condition, are given.

\section{RESULTS}

\section{Neuronal adaptation to inhibition by aggrecan}

Embryonic neurons purified from dissected dorsal root ganglia (Barres et al., 1988) were cultured on substrata containing both the growth-promoting ECM molecule laminin and low levels of the inhibitory proteoglycan aggrecan. Neurons were able to adhere to the substratum and extend axons after $20 \mathrm{hr}$ in culture (Fig. 1A). However, the outgrowth of neurons cultured in the presence of aggrecan (right panel) was less profuse than that of

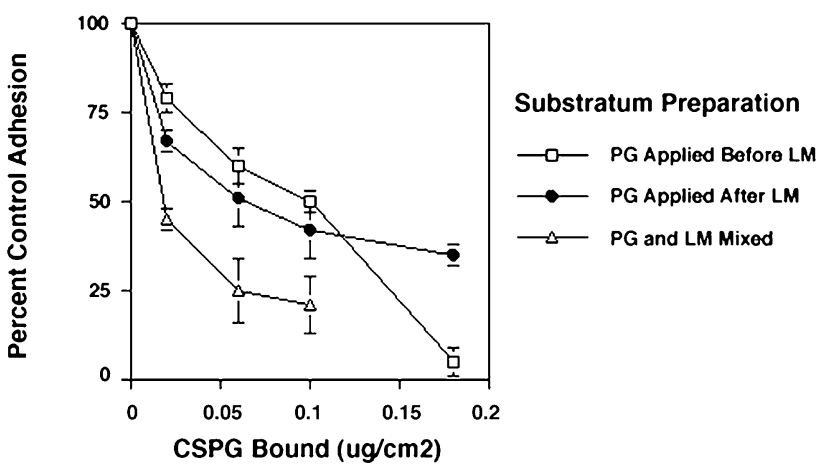

Figure 2. The adhesion of neurons to substrata containing constant amounts of bound laminin (300 ng laminin $/ \mathrm{cm}^{2}$ ) and increasing amounts of bound aggrecan is affected by the order of application of the two proteins to the substrata. Aggrecan mixed with laminin in solution (shaded triangles) is more inhibitory than aggrecan applied before or after adsorption of laminin to the substrata (Mixed points are statistically different from either Before or After at $p<0.05, t$ test), suggesting that conformational changes in laminin may underlie some of the inhibitory effect of aggrecan. At the highest concentrations tested, aggrecan is more inhibitory when applied before laminin, supporting the idea that interactions of soluble laminin with aggrecan result in greater inhibition. Adhesion is given as a percentage of adhesion to control (laminin only) substrata. Means + SEMs from three experiments are given. When error bars do not appear, they are smaller than the size of the symbol.

cells cultured on laminin alone (left panel), suggesting that aggrecan affects either the initiation of neurites or the rate of neurite extension once initiated. Observation of cultures at 3 and $20 \mathrm{hr}$ indicated that the initiation of axons on aggrecan-containing substrata was delayed relative to controls ( $p<0.002, t$ test) (Fig. $1 B)$. Once initiated, axon outgrowth was significantly slower on substrata containing aggrecan for the first several hours of culture ( $p<0.001, t$ test) (Fig. 1C). By $20 \mathrm{hr}$ in culture, however, neurons grown on substrata containing aggrecan had significantly increased their rate of growth such that the rates of axon extension in the presence or absence of low levels of aggrecan were identical (Fig. $1 C$ ). These data indicate that the different substrata are not selecting different neuronal subpopulations with differing abilities to adhere to and extend processes on aggrecan. If neurons that are constitutively able to adhere and extend processes in the presence of aggrecan were being preferentially selected by aggrecan-containing substrata, then there would be no difference between the behavior of cells measured at 3 versus $20 \mathrm{hr}$ in culture. Rather, the improved performance of neurons on aggrecan-containing substrata over time indicates that neurons are able to adapt to the inhibitory effects of aggrecan and extend axons under conditions that initially suppress neurite outgrowth. This adaptation could be mediated either through the upregulation of receptors for growth-promoting molecules that are also present in the substrata or through the downregulation of neuronal receptors for aggrecan in response to low levels of the inhibitor.

The inhibitory effects of aggrecan on neurite initiation and the rate of neurite outgrowth were confirmed by the observation that aggrecan inhibits neuronal cell adhesion to laminin in a dosedependent manner (Fig. 2). In the presence of constant amounts of bound laminin, increasing concentrations of aggrecan significantly reduced the attachment of neuronal cells. It is not currently known how aggrecan inhibits neuronal attachment and outgrowth when co-presented with ECM molecules that promote both neuronal adhesion and outgrowth, such as laminin. If aggre- 
can blocks access of neurons to laminin, the inhibitory effect of aggrecan on outgrowth should not be strongly influenced by the order of application of the two proteins to the substratum, as long as comparable amounts of both molecules are bound in all conditions. However, we observed that the inhibitory potency of aggrecan was significantly affected by the order of application of aggrecan and laminin to the substrata (Fig. 2). Aggrecan adsorbed to the substrata in the presence of soluble laminin was significantly more inhibitory than comparable amounts of proteoglycan bound either before or after the application of laminin. For the highest concentrations of proteoglycan tested, aggrecan bound after laminin (the condition in which simple masking of laminin should be, if anything, most pronounced) was less inhibitory than aggrecan bound before laminin.

\section{Changes in integrin expression are associated with adaptation}

The molecular basis for neuronal adaptation to aggrecan was examined by determining the levels of neuronal receptors for laminin in cells that had been cultured either on laminin alone (300 ng laminin $/ \mathrm{cm}^{2}$ ) or on laminin in combination with low levels of aggrecan (300 ng laminin $/ \mathrm{cm}^{2}, 180 \mathrm{ng}$ aggrecan $/ \mathrm{cm}^{2}$ ). Integrin $\alpha 6 \beta 1$ and $\alpha 3 \beta 1$ are the major laminin receptors in chick ciliary neurons (Weaver et al., 1995) and contribute significantly to the attachment (Condic and Letourneau, 1997) and outgrowth (Tomaselli et al., 1993) of dorsal root ganglion neurons cultured on laminin. Antibodies that block the function of $\beta 1$-containing integrins completely block the attachment and outgrowth of chick sensory neurons on laminin (cf. Tomaselli et al., 1993) and on laminin in combination with aggrecan (data not shown), indicating that neuronal outgrowth on laminin, in either the presence or absence of aggrecan, is integrin dependent.

Cell-surface expression of both integrin $\alpha 6 \beta 1$ and $\alpha 3 \beta 1$ was significantly increased in neurons encountering laminin in the presence of aggrecan (Fig. 3B, Table 1). This increase in integrin cell-surface expression was associated with an increase in integrin mRNA (Fig. $3 A$ ) and total integrin protein (data not shown), all of which increase proportionately in neurons cultured on substrata containing laminin and aggrecan. These results suggest that aggrecan-associated increases in integrin expression are attributable to either transcriptional upregulation or an increase in the stability of the integrin message. Both of these mechanisms are distinct from the posttranslational regulation of integrin expression observed in neurons experiencing low availability of laminin (Condic and Letourneau, 1997), where neurons with increased surface expression of integrins show a concomitant decrease in the levels of integrin mRNA and total protein. The observation that integrin mRNA and protein levels both increase in the presence of aggrecan indicates that the response of neurons to aggrecan cannot be explained simply by aggrecan somehow "masking" laminin to generate a substrate that mimics the effects of low laminin.

Increased expression of integrin $\alpha 3$ and $\alpha 6$ in neurons encountering combined aggrecan and laminin suggests that upregulation of integrin expression by inhibitory CSPGs may underlie the adaptation of neurons to aggrecan. Interestingly, for cells cultured on substrata containing fibronectin and aggrecan (Fig. $3 B$, $F N / P G$, Table 1), integrin expression was not altered either for $\alpha 6 \beta 1$ (a laminin receptor) or for $\alpha 3 \beta 1$ (a receptor for both laminin and fibronectin), suggesting that the interactions of aggrecan with laminin and fibronectin are distinct. This conclusion is supported by the fact that neurons cultured on substrata con-

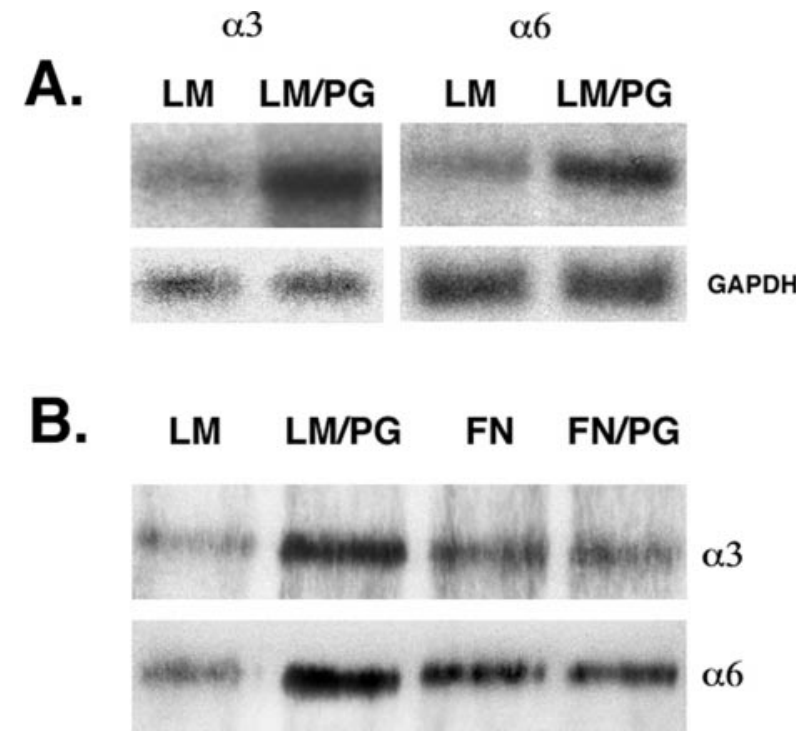

Figure 3. Increased expression of integrin $\alpha 3$ and $\alpha 6$ RNA and cell surface receptor protein in response to aggrecan. Quantifications of the results are given in Table 1. A, Northern analysis of integrin total RNA. The expression of RNA for $\alpha 3$ and $\alpha 6$ integrin is increased in neurons cultured on substrata containing both laminin and aggrecan $(L M / P G)$ relative to those cultured on laminin alone $(L M)$. The blots were stripped and reprobed for GAPDH as a loading control. $B$, Western analysis of biotinylated cell-surface integrin protein. Neurons cultured on substrata containing laminin and aggrecan $(L M / P G)$ show an increase in the expression of laminin receptors integrin $\alpha 3$ and $\alpha 6$ at the cell surface relative to those cultured on laminin alone $(L M)$, whereas the expression of these receptors does not increase in neurons cultured on substrata containing fibronectin and aggrecan $(F N / P G)$ when compared with those cultured on fibronectin alone $(F N)$.

Table 1. Relative amounts of surface protein and RNA on different culture substrata

LM-CSPG/LM

FN-CSPG/FN

\begin{tabular}{lll}
\hline Total RNA & & \\
$\quad \alpha 3$ & $1.91(2.69-1.36)^{*}$ & \\
$\alpha 6$ & $2.24(2.55-1.97)^{*}$ & \\
Surface protein & & \\
$\quad \alpha 3$ & $2.67(4.62-1.55)^{* *}$ & $0.57(1.05-0.31)$ \\
$\alpha 6$ & $2.61(3.09-2.20)^{*}$ & $1.00(1.26-0.79)$
\end{tabular}

The ratios of surface integrin protein and integrin RNA were calculated from densitometry of films derived from at least three experiments (see Materials and Methods). Means and 95\% confidence intervals are given. Statistically different from a ratio of 1 at $* * p<0.1 ;{ }^{*} p<0.05$ ( $t$ test). Ratios of surface protein on FNCSPG/FN are not statistically different from 1 .

taining low levels of aggrecan and laminin adapt to inhibition (Fig. 1), whereas aggrecan continues to inhibit the outgrowth of neurons on fibronectin after $10 \mathrm{hr}$ or more in culture (Snow et al., 1996).

\section{Neurons with high levels of integrin expression are less inhibited by aggrecan}

If alterations in integrin expression play a role in the adaptation of neurons to aggrecan, then increased integrin expression must be associated with changes in neuronal behaviors that are important to neurite outgrowth. Both neuronal adhesion and neurite outgrowth on laminin and on laminin/aggrecan substrata were examined in cells that had been previously cultured on different substrata to manipulate their levels of integrin expression. To 


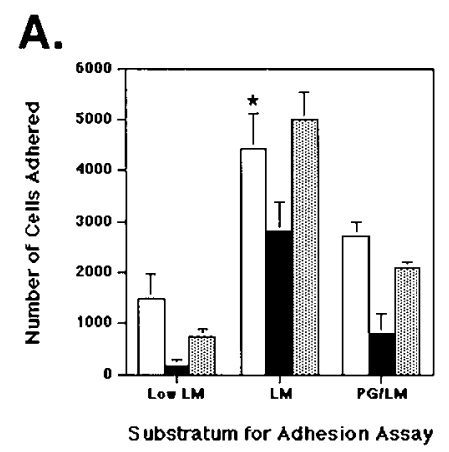

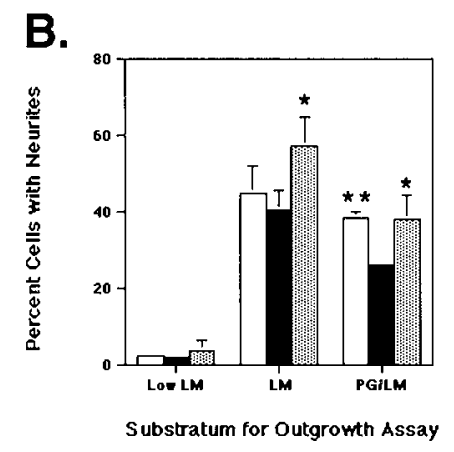

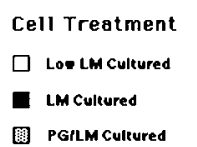

Figure 4. Increased expression of laminin receptors at the cell surface is associated with increased neuronal adhesion and outgrowth. Means + SEMs from three experiments are given. $A$, Neurons expressing high levels of integrin $\alpha 3$ and $\alpha 6$ at the cell surface (Low LM Cultured and $P G / L M$ Cultured) show increased adhesion to laminin and to $P G / L M$ substrata. *Different from LM cultured at $p<0.1$ ( $t$ test). Values for all other low laminin-cultured and PG/LM-cultured conditions are significantly different from LM cultured at $p<0.05$ or better. $B$, Neurons expressing high levels of integrin $\alpha 3$ and $\alpha 6$ at the cell surface extend neurites more readily on laminin both in the presence and absence of the growth inhibitor aggrecan. ${ }^{*}$ Different from LM cultured at $p<0.1$. **Significantly different from LM cultured at $p<0.005$. Where error bars do not appear, they are $<1 \%$.

manipulate surface integrin levels, cells were cultured overnight on laminin, low laminin, or laminin in combination with low levels of aggrecan (see Cell culture and substratum preparation). Cultures on both PG/LM (Fig. 3) and low LM (Condic and Letourneau, 1997) increase integrin expression, apparently by different molecular mechanisms. Cells expressing high levels of $\alpha 6-$ and $\alpha 3$-integrin at the cell surface (i.e., cells cultured either on low laminin or on laminin in combination with aggrecan) were significantly more adherent both to laminin and to laminin/ aggrecan-containing substrata (Fig. 4A). Aggrecan was also less inhibitory to neuronal attachment for cells expressing high levels of integrin $\alpha 3$ and $\alpha 6$ at the cell surface. For control cells (with low expression of integrin $\alpha 3$ and $\alpha 6$ at the cell surface (Fig. $4 A$, black bars), aggrecan in combination with laminin reduced neuronal attachment to $28 \%$ of the levels seen on laminin alone. In contrast, for neurons with high levels of integrin expression (white and gray bars), attachment to aggrecan-containing substrata was considerably closer to that seen on laminin alone; either $61 \%$ (white bars) or $42 \%$ (gray bars) of control adhesion. Similarly, neurons expressing high levels of integrin $\alpha 3$ and $\alpha 6$ at the cell surface extended neurites more readily on inhibitory (PG/LMcontaining) substrata (Fig. 4B). These data indicate that increased cell surface integrin expression allows neurons to overcome inhibition by aggrecan and both attach and extend neurites, despite the presence of inhibitory matrix components in the extracellular environment.

\section{Overexpression of integrin is sufficient for neuronal adaptation to aggrecan}

To determine the role of increased integrin expression in neuronal adaptation to aggrecan, we tested the outgrowth of neurons overexpressing a single laminin receptor (integrin $\alpha 1 \beta 1$ ) in shortterm assays (i.e., time points at which upregulation of endogenous
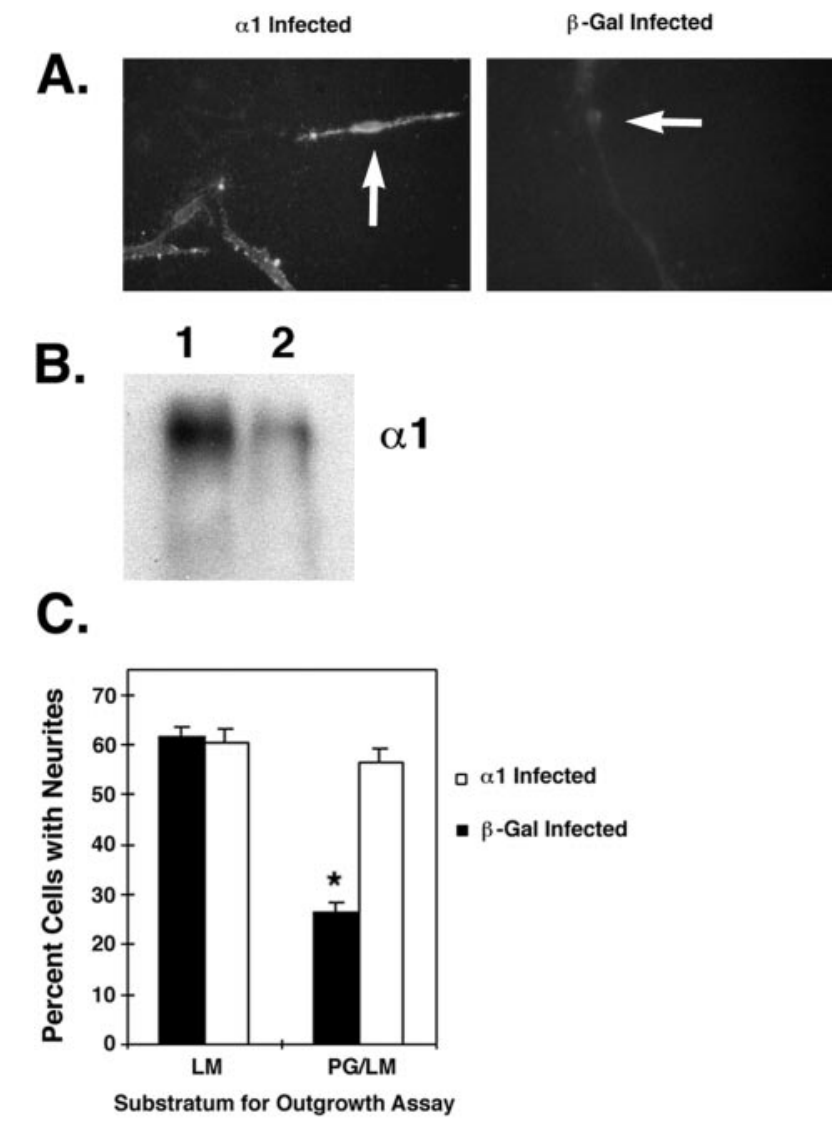

Figure 5. Increased expression of $\alpha 1$-integrin is sufficient to mediate adaptation of neurons to aggrecan. $A$, Neurons infected with adenoviral constructs expressing a control protein $(\beta-G a l$, right $)$ or mouse $\alpha 1$-integrin (left) were stained live with an antibody that specifically recognizes the mouse $\alpha 1$ subunit. Arrows indicate the positions of neuronal cells. $B$, Overexpression of mouse $\alpha 1$-integrin in chick neurons results in an approximately twofold increase in total $\alpha 1$-integrin expressed at the cell surface $(2.25+0.2)$. Infected neurons were cultured on LM substrata, where endogenous integrin expression is low (see Materials and Methods). Cell surface-biotinylated proteins from mouse $\alpha 1$-integrin-infected (lane 1) or control, $\beta$-galactosidase-infected (lane 2) neurons were immunoprecipitated with an antisera that recognizes both mouse and chick $\alpha 1$-integrin subunits. Total $\alpha 1$-integrin expressed at the surface is increased after infection with $\alpha 1$-expressing adenovirus, reflecting the contribution of the exogenous mouse protein to total $\alpha 1$ expression. Expression of endogenous $\alpha 1$ (control cells, lane 2) is quite low under these conditions. $C$, Control or $\alpha 1$-integrin-infected neurons were cultured on substrata containing laminin alone or laminin in combination with aggrecan as in Figure 4. Control neurons expressing $\beta$-galactosidase (black bars) are strongly inhibited in the presence of aggrecan after $3 \mathrm{hr}$ in culture (Figs. 1, 4). At this time in culture, endogenous increases in integrin expression have not yet occurred. Neurons with increased laminin-receptor expression ( $\alpha 1$-expressing; white bars) are not inhibited by aggrecan, showing outgrowth equivalent to that seen on laminin alone. Means + SEMs from at least three experiments are given. *Significantly different from all other conditions at $p<0.0001$ ( $t$ test).

integrins has not yet occurred). Neurons were cultured on laminin substrata $\left(300 \mathrm{ng} / \mathrm{cm}^{2}\right)$. On this substrata, endogenous laminin receptors are expressed at low levels (Fig. 3, $\alpha 3 \beta 1, \alpha 6 \beta 1$; Fig. $5 B, \alpha 1 \beta 1)$. Neurons were infected with adenoviral constructs expressing a full-length mouse $\alpha 1$-integrin subunit. In sensory neurons, $\alpha 1 \beta 1$-integrin functions as a laminin and collagen receptor and is thought to be the receptor primarily responsible for adhesion of dorsal root ganglion neurons to laminin (Tomaselli et al., 1993). Consequently, altering the expression of this receptor 
would be predicted to have the greatest effect on neuronal outgrowth on laminin. In most cells, the $\beta 1$ subunit is synthesized in considerable excess (De Strooper et al., 1991; Muller et al., 1993; Koivisto et al., 1994), and exogenously supplied $\alpha$-subunits are efficiently expressed as $\alpha$ - $\beta 1$ heterodimers at the cell surface (Hayashi et al., 1991; Felsenfeld et al., 1996; Miyakawa et al., 1996). Infection with mouse integrin $\alpha 1$-expressing adenovirus resulted in expression of mouse $\alpha 1$-containing integrins at the surface of all sensory neurons in culture (Fig. 5A). The levels and time course of infection were manipulated to yield an approximately twofold increase $(2.25+0.2)$ in expression of $\alpha 1$ containing integrins at the cell surface (Fig. $5 B$ ). This increase was similar in magnitude to that which occurs naturally in neurons that have adapted to aggrecan (Fig. $3 B$ to Fig. $5 B$ ). Similar to the "adapted" neurons with high levels of integrin expression shown in Figure 4, neurons directly manipulated to express high levels of $\alpha 1$-integrin also showed marked improvement in outgrowth on substrata containing aggrecan (Fig. 5C). At $3 \mathrm{hr}$ in culture, a time point at which upregulation of endogenous integrins has not yet occurred and control neurons are strongly inhibited, neurons expressing high levels of $\alpha 1$-integrin exhibited outgrowth in the presence of aggrecan that was equivalent to that seen on laminin alone. These results demonstrate a causal link between integrin modulation and neuronal adaptation, indicating that increased integrin expression is sufficient to promote the outgrowth of neurons in the presence of aggrecan.

\section{DISCUSSION}

We have shown that integrin expression at the surface of sensory neurons increases in response to low levels of the inhibitory proteoglycan aggrecan, an ECM molecule that is not itself a ligand for integrins. The aggrecan-associated increase in integrin expression occurs through a mechanism that is distinct from that seen in response to low availability of laminin (Fig. 3) (cf. Condic and Letourneau, 1997), indicating that the effects of aggrecan are unlikely to be caused by a simple "masking" of laminin by proteoglycan. Increased integrin expression is correlated with increased neuronal adhesion and neurite outgrowth in the continued presence of the inhibitor. Manipulation of integrin expression directly with adenoviral constructs indicates that high levels of integrin expression are sufficient to mediate adaptation of neurons to aggrecan. The ability of embryonic neurons to adapt to aggrecan suggests that modulation of integrin expression contributes to the regenerative capability of embryonic neurons in the presence of inhibitory proteoglycans after injury. Changes in neuronal responsiveness to laminin as a consequence of exposure to an inhibitory ECM proteoglycan demonstrates that the "cellular history" of a neuron can be a significant factor in neuronal interactions with both positive and negative guidance molecules. The regulation of integrins by aggrecan is significant because it demonstrates that proteoglycans can alter expression of receptors that mediate neuronal interactions with other, nonproteoglycan components of the ECM and because it suggests a possible mechanism for promoting the outgrowth of adult neurons in the presence of inhibitory proteoglycans that are expressed after injury to the nervous system.

There have been conflicting reports regarding the role that CSPGs play in regulating neurite outgrowth. CSPG immunostaining in vivo often localizes to regions of embryos that exclude axons (Snow et al., 1990b; Oakley and Tosney, 1991; Snow et al., 1991; Brittis et al., 1992; Landolt et al., 1995), and CSPGs in vitro can inhibit neurite outgrowth (Snow et al., 1990a; Fichard et al.,
1991; Snow and Letourneau, 1992; Braunewell et al., 1995; Maeda and Noda, 1996; Challacombe et al., 1997). In contrast, CSPG immunostaining in vivo is sometimes correlated with tissues that support the growth of axons (for review, see Pearlman and Sheppard, 1996), and CSPGs in combination with other matrix proteins can constitute a permissive substratum for axon outgrowth under some conditions in vitro (Streit et al., 1993; Faissner et al., 1994) (also see Fig. $1 A$ ). One possible explanation for these conflicting results is that different studies have measured the response of neurons to different species of CSPG. Alternatively, it has been suggested that the growth-inhibiting or growthpromoting properties of CS-containing ECM preparations do not reflect CSPG function but are attributable to the presence of differing CS-binding proteins that in turn mediate the observed effects on neurite outgrowth (Emerling and Lander, 1996). This idea is supported by the fact that proteins known to be inhibitory to neurite outgrowth, including tenascins and thrombospondins, also bind to CS (Winnemoller et al., 1992; Barnea et al., 1994; Grumet et al., 1994). A third possibility is that CSPGs do affect neurite adhesion and outgrowth, but this effect is modulated by the precise combinations or concentrations of molecules present in the ECM (Snow and Letourneau, 1992). For example, the CSPGs versican and decorin inhibit adhesion of sensory neurons to fibronectin but not to laminin or collagen (Braunewell et al., 1995), and both chondroitin sulfate (Dou and Levine, 1995) and the cell surface proteoglycan NG2 (Dou and Levine, 1994) inhibit sensory neuronal outgrowth on laminin but not on the growthpromoting cell-surface molecule L1. A final possibility presented by the current observations is that because inhibitory CSPGs alter the neuronal response to growth-promoting matrix components over time, an individual neuron's response to CSPG can change depending on the length of time it has been in contact with CSPG-containing matrix and the availability of alternative (and perhaps more permissive) substrata for neurite outgrowth.

The adaptive response of neurons to inhibitory matrix components demonstrated here somewhat complicates the definition of "inhibitory." Clearly, aggrecan can arrest the outgrowth of neurons in acute assays when neurons encounter aggrecan in a discrete location and have the option of stopping and/or turning to avoid aggrecan-containing regions (Snow et al., 1990a, 1991; Snow and Letourneau, 1992; Challacombe et al., 1997). Our results demonstrate that under conditions in which neurons do not have the option of extending onto more favorable substrata, they can adjust their surface expression of integrins to compensate for their environment and extend neurites, in agreement with previous reports of limited neurite outgrowth on substrata containing either high amounts of CSPG (Snow et al., 1990a) or increasing steps of CSPG (Snow and Letourneau, 1992). In shortterm assays, aggrecan inhibits neuronal attachment (Figs. 2, 4A), neurite initiation (Fig. $1 B$ ), and rate of neurite outgrowth (Fig. $1 C)$. If only $20 \mathrm{hr}$ cultures had been examined in isolation, none of these effects would have been evident because of the adaptive response of the neurons, and quite different conclusions might have been drawn regarding the properties of aggrecan in this system. The adaptive ability of neurons introduces the concept of cellular "history" into our thinking about how a neuron responds to inhibitory components of the ECM. The past experience of a growth cone may significantly alter the strength and even the nature of a neuron's response to what is currently present in the extracellular environment.

Sensory neurons do not compensate for the inhibitory effects of aggrecan under all circumstances. When cells are cultured on 
substrata containing both fibronectin and aggrecan, the rate of neurite extension remains quite low relative to cells grown on fibronectin alone after $10 \mathrm{hr}$ or more in culture (Snow et al., 1996). The inability of sensory neurons to adapt to aggrecan when cultured on fibronectin is consistent with our observation that expression of the fibronectin receptor $\alpha 3 \beta 1$ is not increased in cells cultured on aggrecan-fibronectin-containing substrata (Fig. 3 , Table 1). Fibronectin is known to interact with CSPGs including aggrecan. The CSPG-binding domains of fibronectin are localized to the IIIcs (or second cell-binding) region of the molecule and to the adjoining type III repeats (no. 12-14) (Barkalow and Schwarzbauer, 1994; Iida et al., 1995). The fibronectin IIIcs domain also contains the binding site for integrin $\alpha 4 \beta 1$ (Iida et al., 1995). Integrins $\alpha 3 \beta 1$ and $\alpha 5 \beta 1$ bind to a different region of the fibronectin molecule, the first cell-binding (or RGD-containing) domain. It is possible that binding of $\alpha 3 \beta 1$ to fibronectin is not affected by the interactions of fibronectin with aggrecan at a remote site in the molecule and that the inhibition of neurite outgrowth observed on substrata containing both fibronectin and aggrecan is largely caused by alterations in integrin $\alpha 4 \beta 1$ activity that are not compensated for by either integrin $\alpha 3 \beta 1$ or $\alpha 5 \beta 1$.

Inhibitory proteoglycans, including aggrecan, are prominent components of the neural extracellular matrix during development, and their expression generally declines postnatally to relatively low levels in the adult (Meyer-Puttlitz et al., 1995; Lebaron, 1996; Levine and Nishiyama, 1996; Margolis et al., 1996; Schwartz et al., 1996). After injury to the CNS, there is a pronounced increase in the expression of both CSPGs and growthpromoting matrix molecules in regions of damage (Hoke and Silver, 1996). In "atraumatic" injury models that prevent the increased expression of proteoglycans normally associated with CNS damage, adult neurons extend considerable distances through the white matter of the brain (Davies et al., 1997), suggesting that inhibitory proteoglycans play a pivotal role in suppressing regeneration. In the spinal cord, many axons near the site of injury do not retract but rather exhibit significant sprouting in the initial weeks after injury. These early sprouts, however, do not continue to extend, and their arrested progress is coincident with the time course for increased CSPG accumulation in and around the site of injury (Li and Raisman, 1994, 1995). In an in vitro model system, McKeon et al. (1995) have shown that CSPG expression associated with cortical injury inhibits axon outgrowth. Treatment with chondroitinase to remove GAG chains from CSPG molecules results in a significant increase in neurite extension over scar tissue derived from CNS injury. Interestingly, co-treatment with both chondroitinase and function-blocking anti-laminin antibodies reverses the growth-promoting effect of chondroitinase alone, suggesting that interactions of neurons with laminin can support regeneration once the inhibitory activity of CSPGs has been reduced (McKeon et al., 1995). Consistent with these results are the findings that inhibitory factors in CNS myelin can be overcome by the addition of laminin (David et al., 1995).

The results presented here indicate that aggrecan is inhibitory to the attachment and outgrowth of neurons in culture. Embryonic neurons are able to compensate for the inhibitory action of aggrecan over time by increasing their expression of integrins and their responsiveness to laminin. Increased integrin expression is sufficient to mediate adaptation of neurons to aggrecan. These results suggest that manipulation of integrin expression may provide a mechanism for increasing the regenerative potential of adult neurons after CNS injury.

\section{REFERENCES}

Balsamo J, Ernst H, Zanin MK, Hoffman S, Lilien J (1995) The interaction of the retina cell surface $\mathrm{N}$-acetylgalactosaminylphosphotransferase with an endogenous proteoglycan ligand results in inhibition of cadherin-mediated adhesion. J Cell Biol 129:1391-1401.

Barkalow FJ, Schwarzbauer JE (1994) Interactions between fibronectin and chondroitin sulfate are modulated by molecular context. J Biol Chem 269:3957-3962.

Barnea G, Grumet M, Milev P, Silvennoinen O, Levy JB, Sap J, Schlessinger J (1994) Receptor tyrosine phosphatase beta is expressed in the form of proteoglycan and binds to the extracellular matrix protein tenascin. J Biol Chem 269:14349-14352.

Barres BA, Silverstein BE, Corey DP, Chun LL (1988) Immunological, morphological, and electrophysiological variation among retinal ganglion cells purified by panning. Neuron 1:791-803.

Braunewell KH, Pesheva P, McCarthy JB, Furcht LT, Schmitz B, Schachner M (1995) Functional involvement of sciatic nerve-derived versican- and decorin-like molecules and other chondroitin sulphate proteoglycans in ECM-mediated cell adhesion and neurite outgrowth. Eur J Neurosci 7:805-814.

Brittis PA, Canning DR, Silver J (1992) Chondroitin sulfate as a regulator of neuronal patterning in the retina. Science 255:733-736.

Caterson B, Christner JE, Baker JR (1983) Identification of a monoclonal antibody that specifically recognizes corneal and skeletal keratan sulfate. J Biol Chem 258:8848-8854.

Challacombe JF, Snow DM, Letourneau PC (1997) Dynamic microtubule ends are required for growth cone turning to avoid an inhibitory guidance cue. J Neurosci 17:3085-3095.

Condic ML, Letourneau PC (1997) Ligand induced changes in integrin expression regulate neuronal adhesion and neurite outgrowth. Nature 389:852-856.

David S, Braun PE, Jackson DL, Kottis V, McKerracher L (1995) Laminin overrides the inhibitory effects of peripheral nervous system and central nervous system myelin-derived inhibitors of neurite growth. J Neurosci Res 42:594-602.

Davies SJ, Fitch MT, Memberg SP, Hall AK, Raisman G, Silver J (1997) Regeneration of adult axons in white matter tracts of the central nervous system. Nature 390:680-683.

de Curtis I, Quaranta V, Tamura RN, Reichardt LF (1991) Laminin receptors in the retina: sequence analysis of the chick integrin alpha 6 subunit. Evidence for transcriptional and posttranslational regulation. J Cell Biol 113:405-416.

De Strooper B, Van Leuven F, Carmeliet G, Van Den Berghe H, Cassiman JJ (1991) Cultured human fibroblasts contain a large pool of precursor beta 1-integrin but lack an intracellular pool of mature subunit. Eur J Biochem 199:25-33.

Dou CL, Levine JM (1994) Inhibition of neurite growth by the NG2 chondroitin sulfate proteoglycan. J Neurosci 14:7616-7628.

Dou CL, Levine JM (1995) Differential effects of glycosaminoglycans on neurite growth on laminin and L1 substrates. J Neurosci 15:8053-8066.

Emerling DE, Lander AD (1996) Inhibitors and promoters of thalamic neuron adhesion and outgrowth in embryonic neocortex: functional association with chondroitin sulfate. Neuron 17:1089-1100.

Ernst H, Zanin MK, Everman D, Hoffman S (1995) Receptor-mediated adhesive and anti-adhesive functions of chondroitin sulfate proteoglycan preparations from embryonic chicken brain. J Cell Sci 108:3807-3816.

Faissner A, Steindler D (1995) Boundaries and inhibitory molecules in developing neural tissues. Glia 13:233-254.

Faissner A, Clement A, Lochter A, Streit A, Mandl C, Schachner M (1994) Isolation of a neural chondroitin sulfate proteoglycan with neurite outgrowth promoting properties. J Cell Biol 126:783-799.

Felsenfeld DP, Choquet D, Sheetz MP (1996) Ligand binding regulates the directed movement of beta1 integrins on fibroblasts. Nature 383:438-440.

Fichard A, Verna J-M, Olivares J, Saxod R (1991) Involvement of a chondroitin sulfate proteoglycan in the avoidance of chick epidermis by dorsal root ganglia fibers: a study using $\beta$-D-xyloside. Dev Biol 148:1-9.

Gomez TM, Letourneau PC (1994) Filopodia initiate choices made by sensory neuron growth cones at laminin/fibronectin borders in vitro. J Neurosci 14:5959-5972.

Graham FL, Prevec L (1995) Methods for construction of adenovirus vectors. Mol Biotechnol 3:207-220.

Grumet M, Milev P, Sakurai T, Karthikeyan L, Bourdon M, Margolis RK, Margolis RU (1994) Interactions with tenascin and differential effects 
on cell adhesion of neurocan and phosphacan, two major chondroitin sulfate proteoglycans of nervous tissue. J Biol Chem 269:12142-12146.

Hayashi Y, Reszka A, Iguchi T, Reinish B, Kawashima T, Horwitz AF (1991) Expression of chicken integrin beta 1 subunit in rat PC12 cells. Cell Struct Funct 16:135-139.

Hoke A, Silver J (1996) Proteoglycans and other repulsive molecules in glial boundaries during development and regeneration of the nervous system. Prog Brain Res 108:149-163.

Iida J, Meijne AM, Spiro RC, Roos E, Furcht LT, McCarthy JB (1995) Spreading and focal contact formation of human melanoma cells in response to the stimulation of both melanoma-associated proteoglycan (NG2) and alpha 4 beta 1 integrin. Cancer Res 55:2177-2185.

Koivisto L, Heino J, Hakkinen L, Larjava H (1994) The size of the intracellular beta 1-integrin precursor pool regulates maturation of beta 1-integrin subunit and associated alpha-subunits. Biochem $\mathbf{J}$ 300:771-779.

Landolt RM, Vaughan L, Winterhalter KH, Zimmermann DR (1995) Versican is selectively expressed in embryonic tissues that act as barriers to neural crest cell migration and axon outgrowth. Development 121:2303-2312.

Lebaron RG (1996) Versican. Perspect Dev Neurobiol 3:261-271.

Letourneau PC, Condic ML, Snow DM (1994) Interactions of developing neurons with the extracellular matrix. J Neurosci 14:915-928.

Levine JM, Nishiyama A (1996) The NG2 chondroitin sulfate proteoglycan: a multifunctional proteoglycan associated with immature cells. Perspect Dev Neurobiol 3:245-259.

Li Y, Raisman G (1994) Schwann cells induce sprouting in motor and sensory axons in the adult rat spinal cord. J Neurosci 14:4050-4063.

Li Y, Raisman G (1995) Sprouts from cut corticospinal axons persist in the presence of astrocytic scarring in long-term lesions of the adult rat spinal cord. Exp Neurol 134:102-111.

Luo Y, Raper JA (1994) Inhibitory factors controlling growth cone motility and guidance. Curr Opin Neurobiol 4:648-654.

Maeda N, Noda M (1996) 6B4 proteoglycan/phosphacan is a repulsive substratum but promotes morphological differentiation of cortical neurons. Development 122:647-658

Margolis RK, Rauch U, Maurel P, Margolis RU (1996) Neurocan and phosphacan: two major nervous tissue-specific chondroitin sulfate proteoglycans. Perspect Dev Neurobiol 3:273-290.

McKeon RJ, Hoke A, Silver J (1995) Injury-induced proteoglycans inhibit the potential for laminin-mediated axon growth on astrocytic scars. Exp Neurol 136:32-43.

Meyer-Puttlitz B, Milev P, Junker E, Zimmer I, Margolis RU, Margolis RK (1995) Chondroitin sulfate and chondroitin/keratan sulfate proteoglycans of nervous tissue: developmental changes of neurocan and phosphacan. J Neurochem 65:2327-2337.

Miyakawa Y, Nishimura T, Ueyama Y, Miyake K, Miyasaka M, Ikeda Y, Habu S (1996) Cell adhesion via murine alpha4 human beta1 integrin chimera on transfected K562 cells to endothelial cells. Exp Cell Res 226:75-79.
Muller AH, Gawantka V, Ding X, Hausen P (1993) Maturation induced internalization of beta 1-integrin by Xenopus oocytes and formation of the maternal integrin pool. Mech Dev 42:77-88.

Oakley RA, Tosney KW (1991) Peanut agglutinin and chondroitin-6sulfate are molecular markers for tissues that act as barriers to axon advance in the avian embryo. Dev Biol 147:187-206.

Pearlman AL, Sheppard AM (1996) Extracellular matrix in early cortical development. Prog Brain Res 108:117-134.

Schwartz NB, Domowicz M, Krueger RCJ, Li H, Mangoura D (1996) Brain aggrecan. Perspect Dev Neurobiol 3:291-306.

Snow DM, Letourneau PC (1992) Neurite outgrowth on a step gradient of chondroitin sulfate proteoglycan (CS-PG). J Neurobiol 23:322-336.

Snow DM, Lemmon V, Carrino DA, Caplan AI, Silver J (1990a) Sulfated proteoglycans in astroglial barriers inhibit neurite outgrowth in vitro. Exp Neurol 109:111-130.

Snow DM, Steindler DA, Silver J (1990b) Molecular and cellular characterization of the glial roof plate of the spinal cord and optic tectum: a possible role for a proteoglycan in the development of an axon barrier. Dev Biol 138:359-376.

Snow DM, Watanabe M, Letourneau PC, Silver J (1991) A chondroitin sulfate proteoglycan may influence the direction of retinal ganglion cell outgrowth. Development 113:1473-1485.

Snow DM, Atkinson PB, Hassinger TD, Letourneau PC, Kater SB (1994) Chondroitin sulfate proteoglycan elevates cytoplasmic calcium in DRG neurons. Dev Biol 166:87-100.

Snow DM, Brown EM, Letourneau PC (1996) Growth cone behavior in the presence of soluble chondroitin sulfate proteoglycan (CSPG), compared to behavior on CSPG bound to laminin or fibronectin. Int J Dev Neurosci 14:331-349.

Song H, Ming G, He Z, Lehmann M, Tessier-Lavigne M, Poo M (1998) Conversion of neuronal growth cone responses from repulsion to attraction by cyclic nucleotides. Science 281:1515-1518.

Streit A, Nolte C, Rasony T, Schachner M (1993) Interaction of astrochondrin with extracellular matrix components and its involvement in astrocyte process formation and cerebellar granule cell migration. J Cell Biol 120:799-814.

Tomaselli KJ, Doherty P, Emmett CJ, Damsky CH, Walsh FS, Reichardt LF (1993) Expression of beta 1 integrins in sensory neurons of the dorsal root ganglion and their functions in neurite outgrowth on two laminin isoforms. J Neurosci 13:4880-4888.

Weaver CD, Yoshida CK, de Curtis I, Reichardt LF (1995) Expression and in vitro function of beta 1-integrin laminin receptors in the developing avian ciliary ganglion. J Neurosci 15:5275-5285.

Winnemoller M, Schon P, Vischer P, Kresse H (1992) Interactions between thrombospondin and the small proteoglycan decorin: interference with cell attachment. Eur J Cell Biol 59:47-55.

Yamagata M, Jaye DL, Sanes JR (1994) Gene transfer to avian embryos with a recombinant adenovirus. Dev Biol 166:355-359. 